\title{
Thermal Radiations Mitigation and Stealth using Egyptians Cotton Fabrics Treated with ZnO Nanoparticles and Chlorophyll
}

\author{
Salah M.Saleh*1, Ahmed F.Gimiee ${ }^{2}$, Hanaa A. Saad ${ }^{3}$ \\ 1,3Department of Textile chemistry, Cotton Research Institute, Agricultural Research Center, \\ Giza, Egypt. P.O Box 12619 \\ ${ }^{2}$ Department of Architecture, Military Technical Collage, Egyptian Armed Forces, Cairo, Egypt
}

\begin{abstract}
The present research examined to develop thermal radiations mitigation and stealth textiles that could protect the objects from detection by various sensors in the wide spectral range. In this research, samples of dyed long stable Egyptian cotton fabric made from Giza 86 which can conceal the object both in the visible (VIS) (380nm-780nm) and near infrared (NIR) $(780 \mathrm{~nm}-1200 \mathrm{~nm})$ radiation spectral range were developed and investigated. The fabric samples treated with different concentrations of chlorophyll extracted from fresh spinach leaves which acts as natural dye in combination with $\mathrm{ZnO}$ nanoparticles and were used to achieve these characteristics. Estimation of chlorophyll content, color measurements of the treated fabric, and chlorophyll thermal mitigation and stealth behavior was tested and evaluated. The results showed noticeable changes of color intensity and significant influence on the spectral reflectance in the VIS-NIR range. We believe that the results of this study would be applicable to developing high performance thermal mitigating smart textile, and also thermal stealth military uniforms powered by recovered waste heat from available sources.
\end{abstract}

KEYWORDS: thermal stealth, thermal mitigation, thermal imaging, Egyptian cotton, Chlorophyll, ZnO nanoparticles

https://doi.org/10.29294/IJASE.8.3.2022.2314-2322

CC2022 Mahendrapublications.com, All rights reserved

\section{INTRODUCTION}

Materials and techniques to hide, blend, disguise, decoy, or disrupt the appearance of military installation and equipment in their backgrounds known as camouflage, concealment and deception(CCD). CCD designation takes fromthe immediate environment, natural, and artificial materials[1]. All surfaces emit radiation at wavelengths dependent on the temperature. For a relatively cool surface, this emission is in the thermal IR region of the spectrum between 3 and $14 \mu \mathrm{m}$. A human body at $36^{\circ} \mathrm{C}$ has an emission maximum at $9.4 \mu \mathrm{m}$, while a background at $20^{\circ} \mathrm{C}$ has a maximum emission at $9.9 \mu \mathrm{m}$. The intensity of the emission is also dependent on the temperature, given by the Stefan-Boltzmman equation, increasing as the temperature increases[2].Thermal detection cameras are gray scale cameras that convert IR energy into electrical signals. As the energy emitted by a surface is dependent on the surface temperature, warmer objects give higher signals than cooler objects. Temperature differences as low as $0.05^{\circ} \mathrm{C}$ can be detected[3]. To conceal an object from thermal emission detection, the observed surface must has the same temperature or has the same emission intensity as the surrounding environment[4]. The procedure usually involves measuring the thermal radiation from a distant object with devices such as an infrared (IR) camera. Infrared imaging is commonly used for many scientific, industrial and military applications such as temperature measurement, heat detection, and night-vision [5]. Camouflage textiles are primarily used by the military and to a lesser extent by hunters. Military camouflage can be in the form of fabrics (uniforms, protection suits, ballistic protection, tents, tarpaulins, backpacks) or nets to protect assets and personnel. The stealth fabric can be described as afabric that covers and protects the body from exposure to the opponent's detection. There are several studies regarding infrared stealth fabrics used dyeing technology [6]. The effect of camouflaging and how background emissivity affects the camouflage mechanism of dyed cotton fabrics near-IR was described [7]. Materials to camouflage textiles to be used in VIS-NIR include conventional textile dyes such as vat [8], disperse [9], sulfur and acid dyes [10], and pigments [11]. It was suggested that NIR camouflaging could be 
achieved by dyeing with more than four colors rather than a single color.An evaluation of a combination of dyeing, dyeing concentration and reflectance with respectto weave of the fabric was pointed out [12]. Cotton and PET/cotton fabrics were dyed by using some vat dyes to resemble the characteristics of greenish leaves. The reflectance of dyed fabrics was markedly influenced by the constitution of dyes in VIS-NIR region and dyed fabrics imitated the reflectance profile of greenish leaf on the basis of NIR camouflage theory [12]. On the other hand, PET and PET/cotton fabrics dyed with C.I. Disperseblue dye to looks like the characteristics of greenish leaves and they showed that this dye plays an important role in NIR green concealment of PET fabrics [9]. Different fabrics can be dyed using a variety of dyes to claim the requirement of NIR camouflage [13]. The bionics studies showed that the Vis-NIR spectra of green plant leaves are mainly produced by colorless tissue structures and colored matters, respectively [14].The most extensive background materials on the earth were green plant leaves which widely simulated in the camoufage materials [15]. Chlorophyll and its derivatives were currently used mainly for thermal radiations mitigation [16]. Chlorophyll is essential in photosynthesis process which allows plants to absorb energy from sunlight in the presence of carbon dioxide from air and water from soil, then produces glucose that is responsible of grow and metabolism of plants and oxygen that is responsible of respiration of all livings organisms[17]. Also, another physical property of chlorophyll is that its ability to absorb light, mostly from the blue portion followed by the red portion of the electromagnetic spectrum, reflecting the green portion color. Nanoparticles of metal oxides are one of the important classes of inorganic pigments. Treatment with nanoparticles was not only maintained the existing properties of textile material but also imparted other textile properties such as repellency, soil release and UVresistance [18]. Nanoparicles of $\mathrm{TiO}_{2}$ and $\mathrm{ZnOis}$ among the metal oxides which are used as pigments, adsorbents, and catalytic supports on fabrics[19]. These nanoparticles have high surface area. The effects of inorganic nanoparticles on camouflage properties of cotton/polyester fabrics were demonstrated [20]. Han et al. [21], pointed out that $\mathrm{TiO}_{2}, \mathrm{ZnO}$ and $\mathrm{Al}_{2} \mathrm{O}_{3}$ nanoparicleswere used in order to make the reflectance behavior of woodland colors to produce dark brown in the UVVIS-NIR bands with the combination with two colored pigments. The fabric treated with metal nanoparticles showed a lower surface temperature, better effects in terms of concealing the body, and reduced infrared emission compared to untreated samples. Recent research for the combination of nanoparticles and dyes for high reflectance and low emissivity at VIS-NIR bandwas investigated. This paper introduced the organic materials introducing chlorophyll as a dyeing material with $\mathrm{ZnO}$ nanoparticles in a new innovative counter measure technique, contributing in opposing thermal reconnaissance surveillance means. This new technique will assist in increasing the capabilities of thermal camouflage of important military installations, especially the military installations located on rural areas, as most air defense forces, commanding posts and many military air force bases.

\section{MATERIALS AND METHODS \\ 2.1. Materials}

Unbleached long stable Egyptian cotton fabrics made from the cotton variety Giza 86 were purchased from Misr-El-Mehala Company for Spinning and Textile- Egypt, with the following specifications: Specimens' size used: $40 \mathrm{~cm} \times 40 \mathrm{~cm}$, Yarn count: 38 x 40 tex (measure unit for yarn), and Weight: $175 \mathrm{~g} / \mathrm{m} 2$.

All chemicals used were of analytical grade using doubly distilled water (18.5 $\mathrm{M}^{\prime} \Omega$.). Sodium hydroxide $(\mathrm{NaOH})$ was analytical grade from (Koch-Light Co.), hydrogen peroxide (30\% LR grade) from (Aldrich Co.), Sodium carbonate (LR grade), sodium silicate $\left(136^{\circ} \mathrm{Tw}, 27 \% \mathrm{SiO}_{2}\right)$, the wetting agent was the commercially Triton X100 supplied from (Merck Co.).Chlorophyll dye extraction was obtained from fresh spinach leaves andZnO nanoparticles (type1) $\sim 30 \mathrm{~nm}$ from Sisco Research Laboratories, Pvt, Ltd, Maharashtra, India.The thermal cameraused is the Fluke Ti20 Imagerhas the followingspecificationrepresented in Table 1.

\subsection{METHODS \\ 2.2.1.Extraction Method}

Chlorophyll extraction process was carried out using the method described by Jinasena et al [22], with minor adaptation. In the first, ten gram of finely cut fresh spinach leaveswas briefly boiled prior to extraction. Grinding and homogenization of leaves were performed at $0^{\circ} \mathrm{C}$ temperatures with $\sim 30 \mathrm{ml}$ of $80 \%$ acetone. It was then centrifuged at $7000 \mathrm{rpm}$ for 5 minutes. The supernatant was transferred and the procedure was repeated till the residue becomes colorless. The absorbance of the solution was read at 645 $\mathrm{nm}$ and $663 \mathrm{~nm}$ against the solvent (acetone) blank. 
Table 1: Thermal camera specifications of Fluke Ti20 Imager

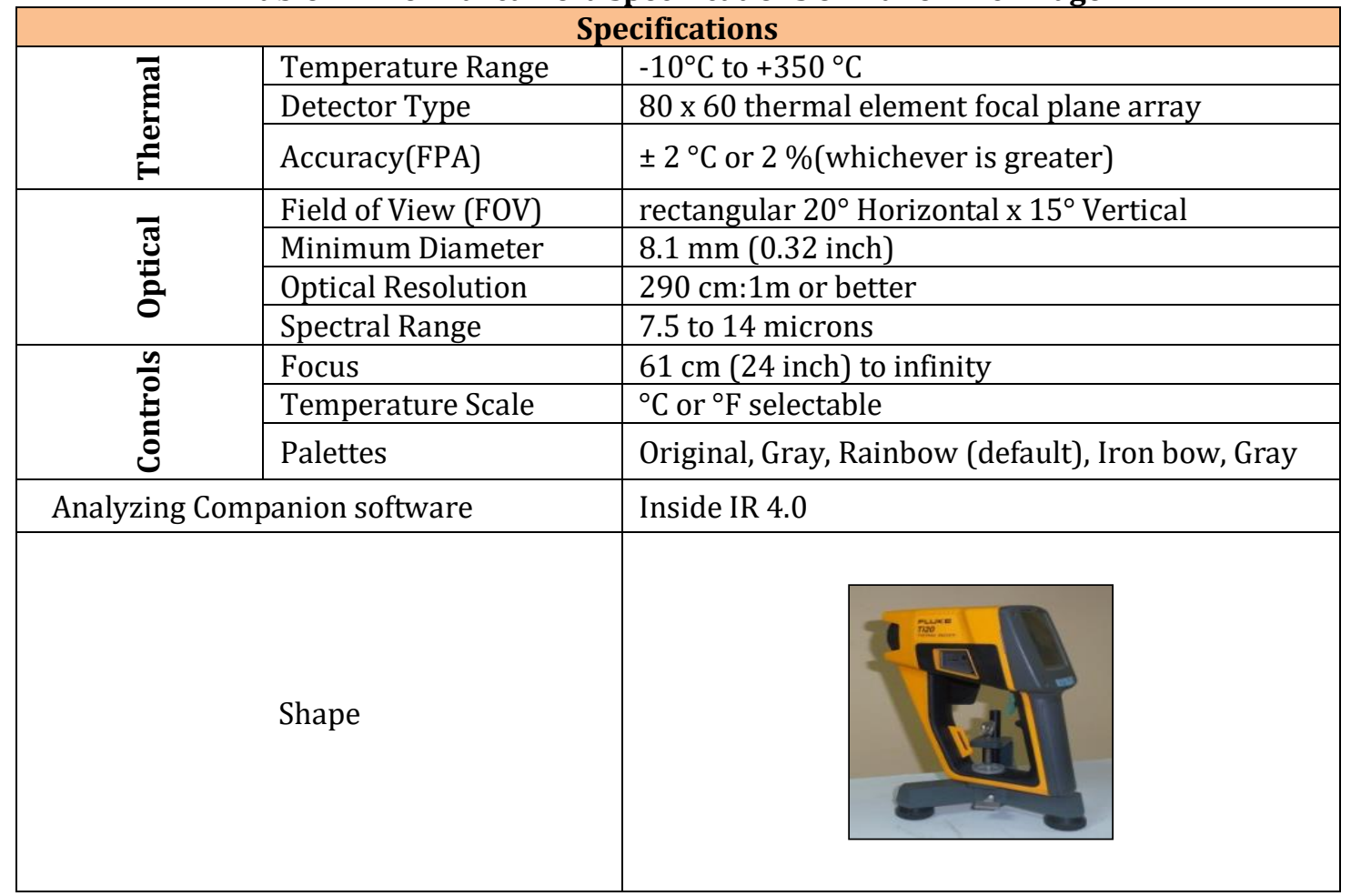

\subsubsection{Scouring and bleaching treatments}

Scouring of the cotton fabric samples was performed by padding the cotton fabric with $3 \%$ $\mathrm{NaOH}$ containing $1.5 \%$ of the wetting agent (Triton X100) in a two-bowel padding mangle adjusting the squeeze pressure to enable $100 \%$ wet pick-up of the fabric and subsequently steamed in a laboratory steamer at $100^{\circ} \mathrm{C}$ for 10 minutes. The scoured cotton fabric was washed with water, neutralized with dilute acetic acid, further washed with water and finally dried in air. Bleaching of the cotton fabric samples was performed by immersed in alkaline bleach $\mathrm{Na}_{2} \mathrm{CO}_{3}(0.2 \mathrm{~g} / \mathrm{l}), \mathrm{NaOH}(1.5 \mathrm{~g} / \mathrm{l}), \mathrm{SiO}_{2}(0.4 \mathrm{~g} / \mathrm{l})$, $\mathrm{MgSO}_{4}(0.2 \mathrm{~g} / \mathrm{l})$, Triton X100 (0.5 g/l) and $\mathrm{H}_{2} \mathrm{O}_{2}$ $\left(10 \mathrm{ml}^{-1}\right)$ were added to the bleaching liquor. The treated cotton fabric samples were removed from the liquor and neutralized with aqueous solution containing $0.1 \%$ acetic acid, followed by a through hot water $\left(80\right.$ to $\left.85^{\circ} \mathrm{C}\right)$ to ensure removal of residual chemicals. Samples were dried in an oven at $100^{\circ} \mathrm{C}$ for 10 minutes.

\subsubsection{Dyeing and coating of cotton fabric}

Dyeing ofthe cotton fabric had been made by the exhaust method at $40^{\circ} \mathrm{C}$ with liquor to material ratio of 30:1. Applying the chlorophyll as the natural dye on the treated cotton fabric was carried out through four consecutive concentrations of chlorophyll $(25 \%, 50 \%, 75 \%$, and $100 \%$ ).The dyed fabrics were then passed through apadding machine to remove excess solution.All samples were padded with a wet pickup of $80 \%$. After padding, $\mathrm{ZnO}$ nanoparticles (average particlesize $30 \mathrm{~nm}$ ) were added $(1 \mathrm{~g} / \mathrm{kg}$ ) in order to investigate their effect on final reflectance of the fabric samples. The sampleswere dried at $85^{\circ} \mathrm{C}$, then treated fabric samples were thoroughly washed, neutralized and dried in air.Finally, the cotton fabric was cured at $160^{\circ} \mathrm{C}$ for three minutes.

\subsubsection{Forming the test model}

The gypsum board material has been chosen, representing the building envelop (the entrance or the exit of an underground command post for example), as it mostly has nearly the same physical characteristics of bricks and concrete construction materials specially (thermal conductivity). To control the internal temperature inside the test model, an electrical thermostat will be attached to the electric circuit of the heating coil, to regulate the electric current passing through it and controls its temperature. This will assist in adjusting the internal space temperature of the test model. From the other side, a thermometer will be fixed to measure the model's internal space temperature. The thermal cameras will be located at a distance of $170 \mathrm{~cm}$ from the 
testing model as this distance is the optimum average distance according to camera manual. All the experimental work have been done in Egyptat $6^{\text {th }}$ October city, as it resemble the typical weather conditions of the urban desert areas, simulating the commanding posts(CP's) on Sinai, Ismailia and Suez cities environmental conditions.

\subsection{Evaluation Tests \\ 2.3.1. Estimation of Chlorophyll content}

The concentrations of chlorophyll a, chlorophyll $\mathrm{b}$ and total chlorophyll were calculated using the following equations:

Chlorophyll a: 12.7(A663) - 2.69(A645),

Chlorophyll b: 22.9(A645) - 4.68(A663), and Total Chlorophyll: 20.2(A645) + 8.02(A663)

\subsubsection{Color measurements of the treated fabric}

The color measurements saturations of all specimens were recordedon the surface of cotton samples with a Spectrophotometer Perkin ElmerModel Lambda 35 with integrated sphere. Measurements were made using a D65 illuminant and 10-degree standard observer, Percentage of reflectance, collected at $10 \mathrm{~nm}$ intervals over the VIS-NIR spectrum (from 380 to $1200 \mathrm{~nm}$ ) and was converted into the CIELAB color system as shown in Figure (1) where: $L^{*}$ describes the lightnessdarkness from white to black.a* and $b^{*}$ describe the chromatic coordinates on the green-red and blue- yellow axis, respectively, Hue angle from red axis (h), and saturation which is distance from red-green axis $\left(\mathrm{C}^{*}\right)$

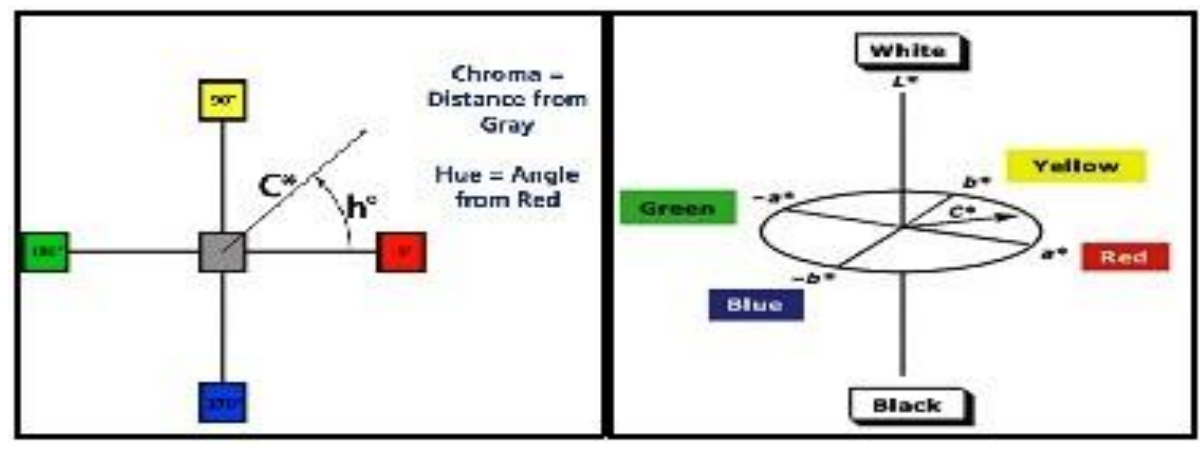

Fig. 1: CIE $1^{*} a^{*} b^{*}$ color system

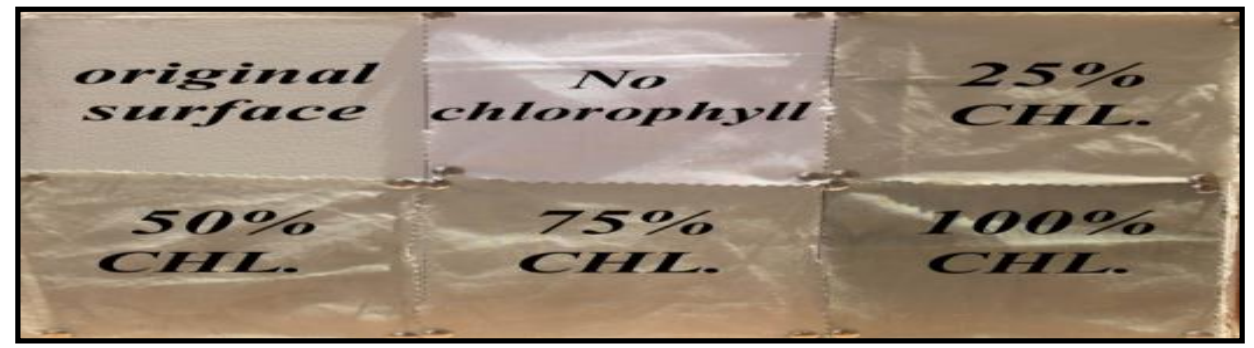

Fig. 2: The gypsum board model portions covered by different chlorophyll concentrations in combination with ZnO nanoparticles

\subsubsection{Comparative experiment of the chlorophyll}

To run up the comparative experiments, the outer surface of the gypsum board model (test model) will be divided into six equal portions: four portionsof them will be covered by a different section of the treated cotton fabric as mentioned above, each of which have a specific chlorophyll concentration as shown in Figure (2). While one portion will be covered with untreated cotton fabric, and another portion will be the original gypsum board (reference portion), to compare their values with the chlorophyll treated portions. The experiment began by adjusting the heating thermostat at $50^{\circ} \mathrm{C}$, from 9:00am leaving the model on the real weather conditions, until thermal shoots were taken every 15 minutes for three consecutive hours starting from 9:00pm using the thermal imager Fluke Ti20.

\section{RESULTS AND DISCUSSION}

It has been noted that chlorophyll is an organic liquid with no adhesive substance in its chemical structure, so, it did not dry even when leaving it

Salah M Saleh et al., 
for more than three days. By adding an adhesive to the chlorophyll, it spoilt the mixture by destroying the chemical ponds between the liquid particles. Also, examining chlorophyll in its liquid condition as a direct paint on the installation surface cannot be done as shown in Figure 3 (a) and (b).By made a modification in the technique of examining the chlorophyll ability by using it as a dye on a cotton fabric screen (screening technique), rather than a paint.

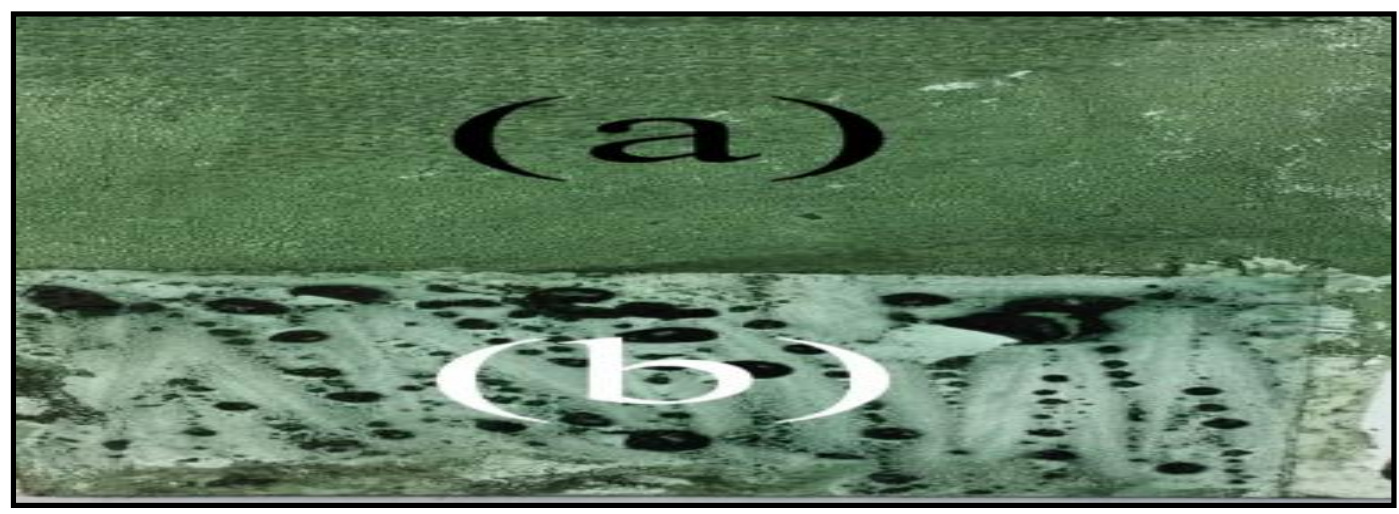

Fig. 3: The liquid chlorophyll appearance when used directly as paint

\subsection{Estimation of Chlorophyll content}

Two types of chlorophyll which are (a) and (b), with a slight difference in chemical composition of side chains, $-\mathrm{CH}_{3}$ and $\mathrm{CHO}$ for chlorophyll $\mathrm{a}$, and $\mathrm{b}$ respectively. These two types of chlorophyll exist in all green plants and algae; complement each other in absorbing sunlight in blue and red wavelengths respectively as demonstrated in Figure (4). Chlorophyll extracts were measured using the equations mentioned above in twodifferent wavelengths $645 \mathrm{~nm}$ and $663 \mathrm{~nm}$ respectively for the calculation of chlorophyll $a_{\text {, }}$ chlorophyll $\mathrm{b}$ and total chlorophyll. The results obtained in Figure (5), revealed that the amount of chlorophyll a, chlorophyll band total chlorophyll was in the range of $(39.6 \mu \mathrm{g} / \mathrm{ml}),(44.1 \mu \mathrm{g} / \mathrm{ml})$ and $(83.7 \mu \mathrm{g} / \mathrm{ml})$ respectively. These results were in accordance with the results obtained by Rajalakshmi \& Banu [23].

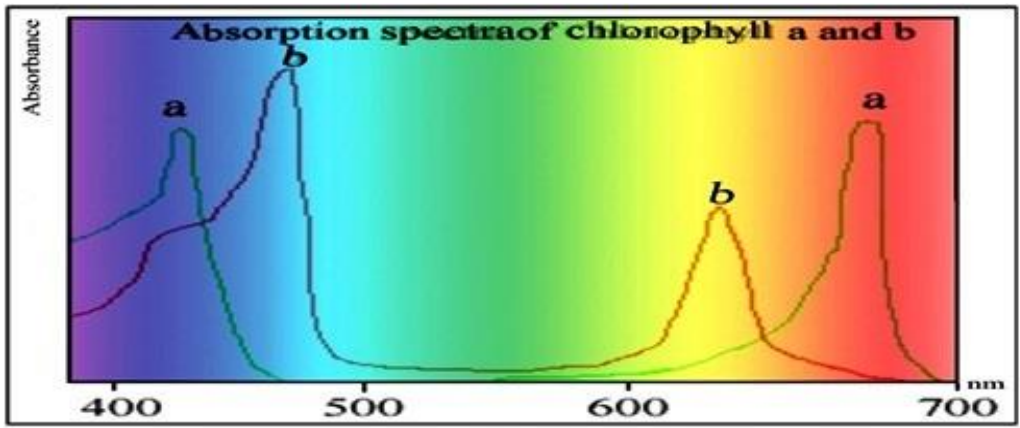

Fig.4 Absorption Spectra of Chlorophyll Types a and b

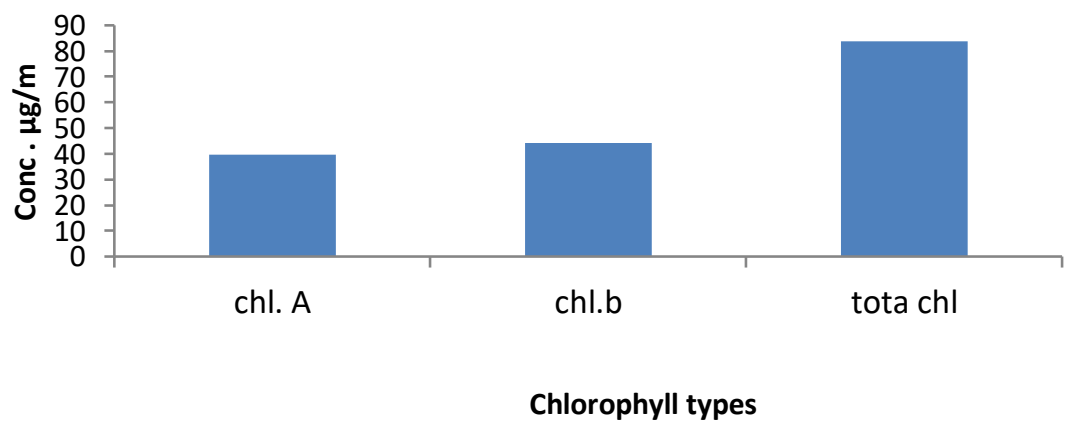

Fig. 5: The amount of chlorophyll types present in spinach leaf extract 


\subsection{Color measurements of the treated fabric}

The changes in color components for cotton sample with different chlorophyll concentrations were shown in Table 2. The results obtained revealed that there were drastic changes of $\mathrm{L}^{*}, \mathrm{a}^{*}$ $b^{*}, c$, and $h$. The data obtained showed that the lightness values reached to $94.54,94.35,93.6$, and 92.63 with chlorophyll concentrations of $25 \%$, $50 \%, 75 \%$, and $100 \%$ respectively. The decrease oflightness $\left(\mathrm{L}^{*}\right)$ values indicates the lower in its luminosity [24]. The $\left(-a^{*}\right)$ value increased with Chlorophyll concentration until reached the maximum value with $100 \%$ of chlorophyll concentration. The $\left(+b^{*}\right)$ value significantly increased with Chlorophyll concentration increased until reach the highest value at chlorophyll concentration 100\%.A significant increase in hue angle (h) was observed as treatment concentration increased from 25\% to $100 \%$. Increase in the color concentration (c) was observed as the Chlorophyll concentration increased till it reached $100 \%$. The spectrophotometer test results confirmed the screens consecutive concentrations of chlorophyll from $25 \%, 50 \%, 75 \%$, to $100 \%$. These results are consistent with the results obtained by Frankel et al [25], that camouflage properties of dyed fabric have direct relation with construction and concentrations of used dyes. Also, a slight increase in range of $550 \mathrm{nmw}$ as obtained because of the reflection of chlorophyll. On the other hand, the presence of $\mathrm{ZnO}$ nanoparticles in the treated fabricresulted in significant changes in color difference of samples in visible band. It was also revealed that the color difference between samples decreased by increasing the number of inorganic nanoparticles.This result may be due to that the presence of $\mathrm{ZnO}$ nanoparticles reduces the light emission and so the reflectance increased and when the color difference of the treated sample was less than of reference fabric, camouflage ability of the samples in the visible band is better [26]. On the other hand, ZnO-loaded cotton $(1 \mathrm{~g} / \mathrm{kg})$ showed a significant effect to restrain cell proliferation as a result of the production of reactive oxygen species. A higher resistance to the cytotoxicity was observed with concentration of $\mathrm{ZnO}$ coated on fabric in our paper. This result was accordance with the results obtained by Yan et al.[27]. It was reported that the cytotoxicity induced by $\mathrm{ZnO}$ nanoparticles was dose-dependent, and the relative survival was below $50 \%$ with a high dose of $\mathrm{ZnO}(0.5 \mathrm{mg} / \mathrm{mL})$. It could be also, due to the $\mathrm{ZnO}$ particles attached to the surface of cotton and few particles entered cells via receptor-mediated endocytosis, which could induce activation of the lysosome membrane and ultimately causes cell death. The presence of $\mathrm{ZnO}$ nanoparticles also, decreases the durability of the cotton fabric. This protection due to the larger surface area per unit mass and volume of nanoparticles which enables such treatments to penetrates into yarn and fabric interstices [28].

Table 2: The Spectrophotometer analysis of the treated fabrics at different chlorophyll concentrations

\begin{tabular}{|c|c|c|c|c|}
\hline C*.C* & $25 \%$ & $50 \%$ & $75 \%$ & $100 \%$ \\
\hline $\mathrm{L}$ & 94.54 & 94.35 & 93.6 & 92.63 \\
\hline$a^{*}$ & 0.85 & -1.05 & -1.10 & -1.13 \\
\hline $\mathrm{b}^{*}$ & 1.6 & 2.04 & 2.04 & 2.15 \\
\hline C & 1.8 & 2.29 & 2.32 & 2.43 \\
\hline $\mathrm{h}$ & 117.19 & 117.65 & 118.06 & 118.37 \\
\hline
\end{tabular}

Where: C.C color components, $C^{*} . C^{*}$ chlorophyll concentrations: C.C color components, $C^{*} . C^{*}$ chlorophyll concentrations

\subsection{Evaluation of chlorophyll thermal mitigation and camouflage behavior}

The average apparent temperatures degrees of thermal imager Fluke Ti20 for each treated cotton fabric had used to draw the average thermal mitigation effect against time (min.) shown in Figure (6). The relationship between apparent temperatures degrees and the averagebackground revealed that the average temperature degree decreased with chlorophyll concentrations increased and also with time compared with the original surface and untreated fabric samples. By analyzing the thermal images taken, the following apparent thermal temperatures could be concluded as shown in Table 3 and their average had been calculated. It can be seen from Table 3 
that the average temperature degrees were proportional to the chlorophyll concentrations. The results obtained revealed that the average temperature degree decreased with chlorophyll concentrations increased and also with time compared with the original surface and untreated fabric samples. The average temperature degrees decreased from $34.3^{\circ} \mathrm{C}, 32.8^{\circ} \mathrm{C}, 32.2^{\circ} \mathrm{C}$, and $31.6^{\circ} \mathrm{C}$ to $34.0^{\circ} \mathrm{C}, 32.5^{\circ} \mathrm{C}, 32.1^{\circ} \mathrm{C}$, and $31.4^{\circ} \mathrm{C}$ for the treated fabrics with chlorophyll concentrations $25 \%, 50 \%, 75 \%$, and $100 \%$ and with time from zero to 180 minutes respectively. On the contrary, the average temperature degree for the original surface and untreated sample increased with time from $36.4^{\circ} \mathrm{C}$, and $34.3^{\circ} \mathrm{C}$ at zero time till it reached $37.4^{\circ} \mathrm{C}$ and $35.1^{\circ} \mathrm{C}$ at 180 minutes respectively.

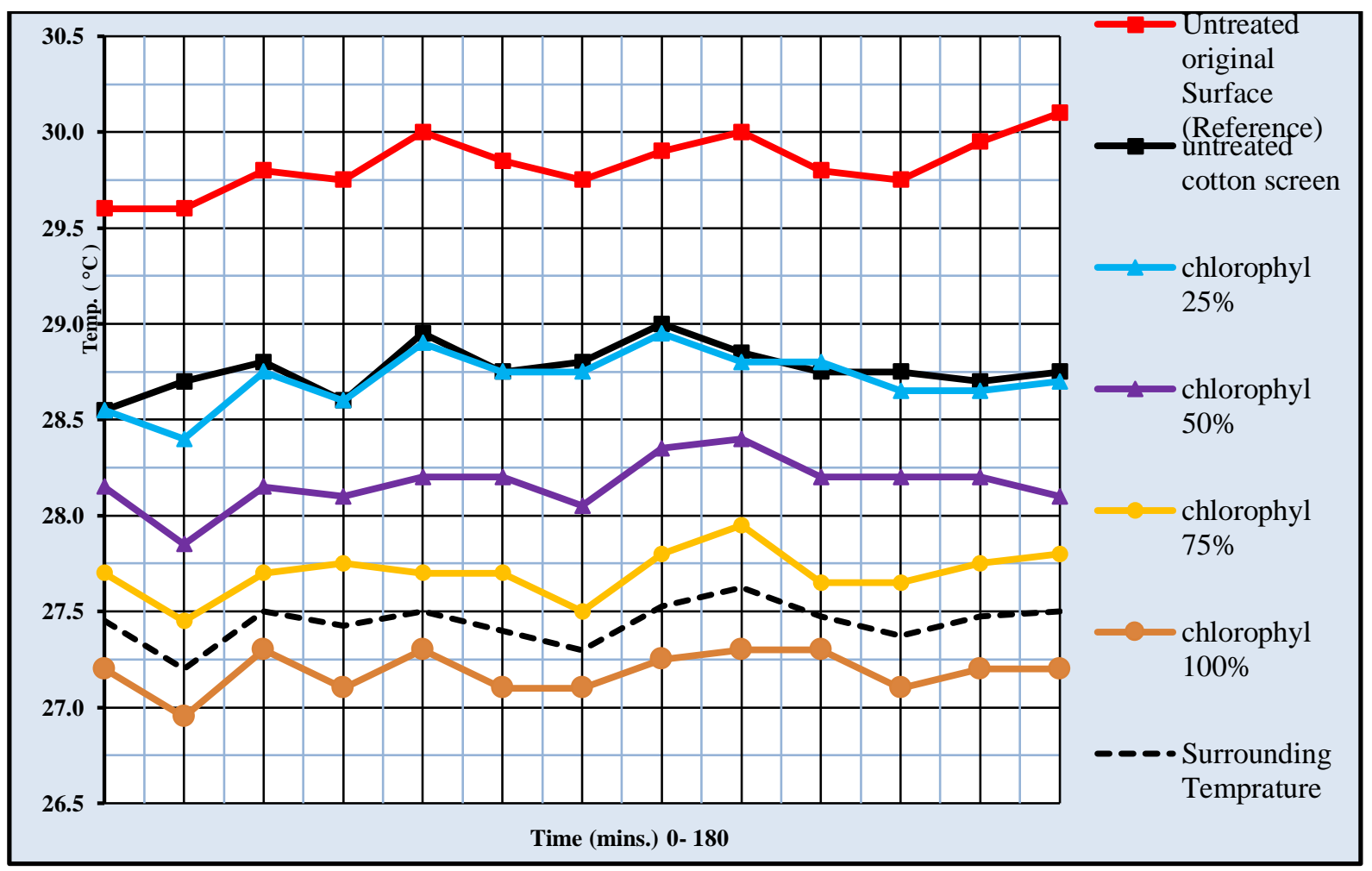

Fig. 6: Effect of different chlorophyll concentrations on the apparent temperature levels vs. time by the thermal imager Fluke Ti20

\subsection{Evaluation of mitigation abilities and thermal contrast values}

Table 4 showed the average mitigation abilities and thermal contrast values of the different chlorophyll concentrations when the average surrounding temperature is $26.1^{\circ} \mathrm{C}$ and average reference temperature is $37.7^{\circ} \mathrm{C}$. For the original surface was that thermal contrast is an index that represents the amount of contrast of an object apparent temperature with its background temperature, where $\mathrm{C}=1$ is the maximum contrast index and as this index become less than one, indicates that the apparent temperature of the object approaches the apparent temperature of its background. In other words, this indicates as the thermal contrast index got smaller means better thermal camouflage efficiency. It can be seen from Table 3 that the thermal camouflage got very good with the treated fabric dyed with $100 \%$ chlorophyll concentration and the thermal contrast reached 0.39 .

\section{CONCLUSION}

This contest introduced and examined an innovations system as thermal mitigation and thermal camouflaging technique in a form of screening technique on extra-long Egyptian cotton fabric screen using chlorophyll as an organic material and natural dye due to its ability in absorbing sunlight in blue and red wavelengths portions of the electromagnetic spectrum between (400-500nm) and (600-700nm) respectively, with the combination with $\mathrm{ZnO}$ nanoparticles. The results obtained revealed that the chlorophyll concentrations have fulfill a significant degree of thermal mitigation but the full saturated cotton fabric with $100 \%$ chlorophyll concentration had performed the best results. The presence of $\mathrm{ZnO}$ nanoparticles in the treated fabric showed that camouflage ability of the samples in the visible 
band is better due to that $\mathrm{ZnO}$ nanoparticles reduces the light emission and so the reflectance increase. The results showed that there should be a great effort in producing chlorophyll in the national field, since it can be extracted from green plants and algae which there are plenty of them exist in Egypt; especially it has a lot of industrial use that must be figured. The results of this study would be applicable to developing high performance thermal mitigating smart textile, and also thermal stealth military.

Table 3: Average temperature degrees $\left({ }^{\circ} \mathrm{C}\right)$ with chlorophyll concentrations

\begin{tabular}{|l|c|c|c|c|c|c|c|c|c|c|c|c|c|}
\hline \multicolumn{1}{|c|}{ Material } & $\mathbf{0}$ & $\mathbf{1 5}$ & $\mathbf{3 0}$ & $\mathbf{4 5}$ & $\mathbf{6 0}$ & $\mathbf{7 5}$ & $\mathbf{9 0}$ & $\mathbf{1 0 5}$ & $\mathbf{1 2 0}$ & $\mathbf{1 3 5}$ & $\mathbf{1 5 0}$ & $\mathbf{1 6 5}$ & $\mathbf{1 8 0}$ \\
\hline $\mathbf{0 . S}$ & 36.8 & 37.4 & 37.2 & 37.4 & 37.2 & 37.4 & 37.4 & 37.5 & 37.5 & 37.4 & 37.5 & 37.4 & 37.4 \\
\hline No C*.C* & 34.3 & 34.7 & 35.1 & 35.1 & 35.1 & 35.1 & 35.1 & 35.2 & 35.2 & 35.2 & 35.1 & 35.1 & 35.1 \\
\hline C*.C*.25\% $^{*} 34.3$ & 34.5 & 35.1 & 35.1 & 35.1 & 35.0 & 35.0 & 35.0 & 35.0 & 35.0 & 35.1 & 35.0 & 34.0 \\
\hline C*.C*.50\% $^{*} 32.8$ & 33.6 & 33.4 & 33.5 & 33.3 & 33.5 & 33.4 & 33.4 & 33.4 & 33.4 & 33.5 & 33.5 & 32.5 \\
\hline C*.C*.75\% $^{*} 32.2$ & 33.1 & 33 & 33 & 33.1 & 33.1 & 33.0 & 33.2 & 33.2 & 33.1 & 33.1 & 33.1 & 32.1 \\
\hline C*.C*.100\% $^{*}$ & 31.6 & 31.3 & 31.6 & 31.6 & 31.3 & 31.5 & 31.4 & 31.3 & 31.3 & 31.5 & 31.5 & 31.4 & 31.4 \\
\hline
\end{tabular}

Where O.S original Surface, $C^{*} . C^{*}$ as shown in Table 2reached 0.39.

Table 4: The average mitigation abilities and thermal contrast values of the different treated cotton fabrics

\begin{tabular}{|l|c|c|c|c|c|}
\hline \multicolumn{1}{|c|}{ C*.C* $^{*}$} & M. S. T. ${ }^{\circ} \mathrm{C}$ & Th. M. Vs. R. T. ${ }^{\circ} \mathbf{C}$ & P. of m. & Th. Cont. & Th. M. a. \\
\hline O.S & 37.7 & 0.00 & $00 \%$ & 0.00 & 0.00 \\
\hline No C*.C* & 35.7 & 2.0 & $-5.3 \%$ & 0.56 & $4.4 \%$ \\
\hline C*.C*.25\% & 35.4 & 2.3 & $-6.1 \%$ & 0.54 & $4.9 \%$ \\
\hline C*.C*.50\% & 34.2 & 3.5 & $-9.3 \%$ & 0.49 & $7.4 \%$ \\
\hline C*.C*.75\% & 33.7 & 4.0 & $-10.6 \%$ & 0.47 & $8.9 \%$ \\
\hline C*.C*.100\% & 32.1 & 5.6 & $-14.9 \%$ & 0.39 & $11.8 \%$ \\
\hline
\end{tabular}

Where M. S. T. Material surface temp,Th. M. Vs. R. T. Thermal mitigation Vs. reference temp, P. of m. Percentage of mitigation, Th. Cont. thermal contrast, and Th. M. a thermal mitigation ability

\section{REFERENCES}

[1] Scott, G., Russell, W, G.,2000. The Art of Darkness: Deception and Urban Operations, RAND (USA).

[2] Howell,J, R., Menguc, M, P., Siegel, R., 2010. Thermal radiation heat transfer. 5 th edition, CRC Press, Boca Raton.

[3] Flir Systems Inc, 2016. Flir, the world's sixth sense. Available from:

http://www.flir.com/Home/ (accessed 19.09.16).

[4] Lee, B., 1999. Theoretical prediction and measurement of the fabric surface apparent temperature in a simulated man/fabric/environment system. Report
No. DSTO, DST0-TR-0849, Melbourne Australia.

[5] Long,., David, D, O., Emi, K., Ward, G., Michael, A,Shenka., Alon, A, G., 2015. Infrared invisibility stickers inspired by cephalopods. J. Mater. Chem. C 3, 64936498.

[6] Zhou, L., Shao, J, Z., Chai, L, Q., 2010. Study on the camouflage- protective and dyeing properties of natural dye indigo. Journal of Donghua University (English Edition), (1), 46-51.

[7] Xu, Y, Y., Cai,Z, S., He, K, L., Zhang, J, L., 2009. Near-infrared camouflage of cotton fabric under different background. Textile 
Auxiliaries, 3. Retrieved from http://en.cnki.com.cn/Article_en/CJFDTOT AL-YRZJ200903005.htm.

[8] Goudarzi, U., Mokhtari, J., Nouri, M., 2013. Camouflage of Cotton Fabrics in Visible and Near Infrared Region Using Vat Dyes, Color Sci. Tech, 7, 25-35.

[9] Zhang, H., Zhang, J, Ch., 2007. Near-infrared green camouflage of cotton fabrics using disperse dyes. SEN'1 GAKKAISHI, 63(10), 223-229.

[10] Puzikova, N, P., Uvarova, E, V., Filyaev, I, M., Yarovaya, L, A., 2008. Principles of an approach for coloring military camouflage, Fiber Chem., 2, 155-159.

[11] KhajehMehrizi, M., Bokaei, F.,Jamshidi, N., 2015. Visible-near infrared concealment of cotton/nylon fabrics using colored pigments and multiwalled carbon nanotube particles (MWCNTs), Color Res. Appl., 1, 93-98.

[12] Zhang, H., Zhang, J. Ch., 2008. Near-infrared green camouflage of cotton fabrics using vat dyes. The Journal of the Textile Institute, 99(1), 83-88.

[13] Coleman, R, A., 1974. Application of infrared absorbers to nylon 6,6. Technical Report (ADA000832), American Cyanamid Company, distributed by National Technical Information Service U. S. department of commerce, prepared for: Army Natick Laboratories.

[14] Blackburn, G, A., Steele, C, M., 1999. Towards the remote sensing of material vegetation physiology: Relationships between spectral reflectance, pigment, and biophysical characteristics of semiarid bushland canopies. Remote Sensing of Environment, 70, 278-292.

[15] Qixin, Lu., Min, Li., Anli, T., Shaohai, F., 2022. Green Plant Leaf-inspired Smart CamouflageFabrics for Visible Light and Near-infrared Stealth. Journal of Bionic Engineering, published online: 18 February.

[16] Yang, Y, J., Liu, Z, M., Hu, B, R., Man, Y, H., Wu, W, J., 2010. Bionic composite material simulating the optical spectra of plant leaves. Journal of Bionic Engineering, 7, S43-S49.

[17] George, C., Papageorgiou., Govindje., 1995. Chlorophyll Fluorescence: A Signature of Photosynthesis Australian Journal of Plant Physiology, Vol. 22: 131-160.
[18] Mahltig, B., Helfried, H., Horst, B,.2005. Functionalization of Textiles by InorganicSol-Gel Coatings; J. Mater. Chem. 15: 4385-4398.

[19] Bendiganavale, A, K., Malshe, V, C., 2008. Infrared reflective inorganic pigments, Recent Pat.Chem. Eng, 1, 67-79.

[20] Jafari, H., Khajeh Mehrizi, M., Fattahi, S., 2016. The effect of Inorganic Nanoparticles on Camouflage Properties of Cotton/Polyester Fabrics. Prog. Color Colorants Coat. 9 29-40.

[21] Han, H, R., Park, Y., Yun. C., Park, C., 2018. Heat transfer characteristics of aluminum sputtered fabrics. Journal of Engineered Fibers and Fabrics, 13(3), 37-44.

[22] Jinasena1, M., Amarasinghe, S., Amarasinghe., Prashantha, B.,2016. Extraction and degradation of chlorophyll a and $b$ from Alternantherasessilis. J. Natn. Sci. Foundation Sri Lanka 44 (1): 11 - 21.

[23] Rajalakshmi, K., Banu, N., 2015. Extraction and Estimation of Chlorophyll from Medicinal Plants. International Journal of Science and Research (IJSR) 4(11), 209-212.

[24] Fraser, B., Murphy. C., Bunting, F., 2002. Real world color management: Pearson Education, 2nd edition, Peachpit Press.

[25] Frankel, K., Sousa, S., Cowan, R., King, M., 2004. Concealment of the warfighter's equipment through enhanced polymer technology. INVISTA Wilmington, DE 19805, INVISTA Sabine, TX, U.S. Army Natick Soldier Center Natick, Massachusetts,

[26] Soumya, S., Peer, M, A., Kiran, M., Ananthakumar, S., 2015. Enhanced nearinfrared reflectance and functional characteristics of Al-doped $\mathrm{ZnO}$ nanopigments embedded PMMA coatings. Solar energy materials \& Solar cells, 143, 335346.

[27] Yan, D.,Yin, G., Huang, Z., Li, L., Liao, X., Xianchun, C., Yao, Y., Hao, B ., 2011. Cellular compatibility of biomineralized $\mathrm{ZnO}$ nanoparticles based on prokaryotic and eukaryotic systems. Langmuir 27(21), 13206.

[28] Patra, J, K., Gouda, S., 2013.Applications of Nanotechnology in Textile Engineering: An overview, Journal of engineering and technology research, (5) 5, 104-111. 